\title{
STRUKTUR SEMANTIS VERBA 'NAIK’ DALAM BAHASA JEPANG
}

\author{
Made Henra Dwikarmawan Sudipa', \\ STIBA Saraswati Denpasar \\ I Ketut Darma Laksana ${ }^{2}$, I Made Rajeg ${ }^{3}$ \\ Program Magister Ilmu Linguistik \\ Fakultas Ilmu Budaya Universitas Udayana \\ Jalan Nias No.13, Denpasar,Bali, Telepon (0361) 250033 \\ 'Email: henradwikarmawan@gmail.com \\ 2Email: darmalaksana27@yahoo.com \\ 3Email: made_rajeg@unud.ac.id
}

\begin{abstract}
Abstrak-Artikel ini berfokus pada analisis struktur semantis verba 'naik' dalam bahasa Jepang. Data dikumpulkan dari artikel koran pada laman asahi.com menggunakan metode simak disertai teknik catat. Data dianalisis menggunakan metode agih. Metode agih digunakan untuk menganalisis struktur semantis dengan teori Metabahasa Semantik Alami (MSA) menurut Goddard dan Wierzbicka (2014). Berdasarkan hasil analisis, verba 'naik' bahasa Jepang terdiri atas verba noru, noboru, dan agaru. Setiap verba memiliki ciri-ciri yang membedakan satu verba dengan verba lainnya.
\end{abstract}

Kata Kunci: struktur semantis, verba, naik, bahasa Jepang

Abstract-This article focuses in analyzing the semantic structure of 'go up' verb in Japanese language. The data was collected from newspaper article from website asahi.com by observation method and notetaking techniques. The data was analyzed using distribution method. Distribution method was used to analyze semantic structure by using Natural Semantic Metalanguage (NSM) theory developed by Goddard and Wierzbicka (2014). The results shows that 'go up' verb in Japanese Language consists of verb noru, noboru, and agaru. Each verb had distinctive features that differentiate one verb to the others.

Key Words: semantic structure, verbs, go up, Japanese

\section{PENDAHULUAN}

Sebuah bahasa memiliki sekumpulan leksikon yang maknanya sulit dibedakan satu sama lain. Sebagai contoh, bahasa Indonesia memiliki leksikon pintar, pandai, dan cakap yang maknanya mirip. Bahasa Inggris memiliki leksikon buy dan purchase yang sama-sama memiliki makna 'membeli'. Bahasa Bali memiliki sejumlah leksikon yang menyatakan 
makna 'makan', seperti ngrayunang, ngajeng, daar, ngamah, dan sebagainya.

Kemiripan makna yang dimiliki suatu leksikon juga terdapat dalam bahasa Jepang. Salah satunya verba yang bermakna 'naik' dalam bahasa Jepang (VNBJ). Terdapat tiga verba yang menyatakan 'naik', yaitu noru, noboru, dan agaru. Berikut contoh pemakaian dari ketiga verba tersebut.

\section{(1-1) Kisha ni noru.}

'Naik kereta api.'

\section{(1-2) Yama ni noboru.}

'Naik gunung.'

\section{(1-3) Kaidan o agaru.}

'Naik ke tangga.'

Berdasarkan contoh kalimat di atas, verba noru, noboru, dan agaru memiliki makna yang mirip satu sama lain. Apabila kurang memahami makna ketiga verba tersebut, kemungkinan menganggap ketiga verba tersebut dapat saling menggantikan satu sama lain. Setiap bentuk mewakili makna yang berbeda, sehingga sekelompok leksikon yang saling bersinonim tidak seratus persen memiliki makna yang sama (Suputra, 2016:154).

Dalam memahami makna suatu leksikon, pembelajar tidak cukup hanya mengetahui makna kamusnya. Setiap leksikon memiliki fitur-fitur yang pembeda sehingga perlu diuraikan lebih rinci lagi (Citrawati, 2018:64). Wierzbicka
(1996) menyatakan bahwa untuk menentukan makna sebuah kata, perlu diketahui struktur semantisnya. Dalam menggali struktur semantis, Wierzbicka menawarkan sebuah teori yang paling mendekati dalam menguraikan struktur semantis sebuah kata yaitu teori Metabahasa Semantik Alami (MSA) yang bekerja dengan menggunakan perangkat 'makna asali'. Ia meyakini bahwa tanpa perangkat makna asali semua deskripsi makna secara aktual atau secara potensial akan menjadi kabur 'obscure' dan berputar-putar 'circularity'.

\section{METODE PENELITIAN}

Penelitian ini menggunakan sumber data berupa artikel koran yang diterbitkan pada laman asahi.com. Laman ini merupakan bagian dari asahi shimbun, salah satu surat kabar nasional Jepang yang terbit sejak 1874 hingga sekarang. Sumber data ini digunakan karena memuat kalimat bahasa Jepang yang standar dan mudah dimengerti. Data dikumpulkan menggunakan metode simak disertai teknik dasar catat. Metode simak dipilih karena objek yang diteliti berupa bahasa yang sifatnya teks (Sudaryanto, 2015:205206).

Metode yang digunakan dalam menganalisis data adalah metode agih. Metode ini disertai dengan teknik ubah ujud parafrasal, yaitu mengubah wujud salah satu atau beberapa 
unsur satuan lingual yang bersangkutan (Sudaryanto, 2015:45). Teknik ini digunakan dalam menganalisis struktur semantis verba noru, noboru, dan agaru dengan menggunakan teori MSA.

Dalam menggali struktur semantis, Wierzbicka (1996) menawarkan sebuah teori yang paling mendekati dalam menguraikan struktur semantis sebuah kata yaitu teori Metabahasa Semantik Alami (MSA). Asumsi teori MSA berkaitan dengan prinsip semiotik yang menyatakan bahwa makna kompleks dapat dijelaskan tanpa harus berputar-putar dan tanpa residu dalam kombinasi makna diskret lainnya. Hal ini tampak jelas dalam kutipan berikut:

A sign cannot be reduced to or analysed into any combination of things which are not themselves signs; consequently, it is impossible to reduce meanings to any combination of things which are not themselves things.

(Goddard,1996:24)

Teori MSA adalah teori semantik yang dapat merumuskan makna yang bersifat universal yang diambil dari bahasa alami untuk menentukan makna kata, makna gramatikal dan makna wacana yang diekspresikan dalam bahasa dan pengaturan budaya. Teori ini juga disertai konsep teoretis berupa makna asali (semantic prime) dan polisemi takkomposisi (noncompositional polysemy). Makna asali merupakan seperangkat makna yang tidak dapat berubah dan telah diwarisi oleh manusia sejak lahir. Polisemi takkomposisi adalah bentuk leksikon tunggal yang dapat mengekspresikan dua buah makna asali yang berbeda (Wierzbicka, 1996:27-29). Sebagai contoh MELAKUKAN dan TERJADI (Goddard, 1996:29).

Setelah menemukan makna asali dan polisemi takkomposisi, langkah selanjutnya dalam analisis struktur semantis VNBJ adalah parafrasa. Parafrasa memiliki lima kaidah penting yang harus diperhatikan. Berikut lima kaidah yang dirumuskan oleh Wierzbicka (1996:35).

1. Menggunakan kombinasi sejumlah makna asali yang terkait dengan klaim teori MSA. Suatu bentuk tidak dapat diuraikan hanya dengan satu makna asali.

2. Memakai unsur-unsur keunikan suatu bahasa dalam menguraikan makna.

3. Mengikuti kaidah sintaksis bahasa.

4. Menggunakan bahasa yang sederhana.

5. Membutuhkan indentitas dan ukuran spasi khusus.

Setelah data dianalisis, tahap selanjutnya ialah penyajian hasil analisis. Tahap penyajian hasil analisis merupakan suatu tahap penelitian yang berupa penyusunan laporan dengan menerapkan metode informal. Metode informal adalah metode yang menguraikan hasil analisis dengan kata-kata biasa (Sudaryanto, 2015:241). 


\section{HASIL DAN PEMBAHASAN}

VNBJ merepresentasikan prototipe action, event, and movement yang terdiri dari makna asali DO 'MELAKUKAN', HAPPEN 'TERJADI', dan MOVE 'BERGERAK' (Goddard dan Wierzbicka, 2014:12). Bertumpu pada tiga makna asali tersebut, VNBJ termasuk dalam kategori makna asali MOVE 'BERGERAK'. VNBJ mengindikasikan seseorang bergerak ke suatu tempat, sehingga terjadi perpindahan dari bawah ke atas. Dalam hal ini, VNBJ berpolisemi dengan BERGERAK/ TERJADI dengan pola sintaksis ' $\mathrm{X}$ bergerak ke Y'. Dalam bahasa Jepang, verba 'naik' dapat direalisasikan secara leksikal dengan noru, noboru, dan agaru. Berikut dipaparkan analisis struktur semantis ketiga verba tersebut.

\subsection{Struktur Semantis Verba Noru}

Verba noru menyatakan makna 'seseorang menempatkan dirinya dalam mobil, kuda, dan sebagainya untuk bergerak ke tempat lain' (Shinmeikai, 1989:1008). Berikut dipaparkan kalimat yang mengandung verba noru.

(4-1) Yaku 10 pun ato Niigata-shi yakusho houman ni manabi shuppatsu suru basu ni noru hito wa 10-nin mo i-na-katta
'Setelah sekitar 10 menit, tidak ada sampai 10 orang yang naik bus ke kantor pemerintah kota Niigata.'

(Kano, 2018)

(4-2) Tomo ni sakunen to onaji yakugara de uma ni nori, kachuu sugata de shinai o pareedo suru.

'Bersama-sama dengan peran yang sama dengan tahun lalu, mereka naik kuda dan berparade di tengah kota dengan sosok mengenakan baju baja'

(Murano, 2018)

(4-3) Heya ga aru 3-kai kara erebeetaa ni noru toki, hoka no nyuukyosha ga namida o nagashite miokutta.

'Saat naik lift dari kamar lantai 3, penghuni lain mengantar sambil mengeluarkan air mata.'

(Ikuta, 2018)

Berdasarkan data kalimat sebelumnya, verba noru menunjukkan tindakan seseorang menaiki sesuatu. Verba noru menghasilkan polisemi BERGERAK/TERJADI dimana seseorang bergerak ke atas atau ke dalam sesuatu, sehingga membentuk pola sintaksis ' $\mathrm{X}$ bergerak ke atas atau ke dalam Y'. Jika dilihat dari entitas yang dikenai tindakan, verba noru menggunakan entitas seperti bus, kuda, lift, dan lain sebagainya. Entitas tersebut menunjukkan sesuatu yang dapat bergerak. Hal ini dapat diformulasikan dengan komponen 'Y merupakan sesuatu yang dapat bergerak'. Kemudian, verba noru juga mengindikasikan bahwa seseorang melakukan 
tindakan tersebut dengan tujuan pergi ke suatu tempat. Hal ini dapat diformulasikan dengan ' $\mathrm{X}$ melakukan ini karena ingin bergerak ke suatu tempat'. Berdasarkan pemaparan ini, verba noru dapat diparafrasekan sebagai berikut.

\section{Noru 'naik/mengendarai/menunggang'} pada waktu itu, $\mathrm{X}$ bergerak ke atas atau ke dalam Y

Y merupakan sesuatu yang dapat bergerak $\mathrm{X}$ melakukan ini karena ingin bergerak ke suatu tempat

$\mathrm{X}$ menginginkan ini

$\mathrm{X}$ melakukan sesuatu seperti ini

\subsection{Struktur Semantis Verba Noboru}

Verba noboru menyatakan makna 'bergerak menuju tempat yang tinggi' (Shinmeikai, 1989:1006). Hirose (2001:5) mengungkapkan bahwa verba noboru menyatakan 'bergerak dari posisi bawah menuju ke atas, dengan fokus pada proses menuju ke atas'. Berikut dipaparkan kalimat yang mengandung verba noboru.

(4-4) Kuruma de 20-pun Osaka-fu Chihayaakasaka-mura no dozanguchi made iki, 1-jikan 10-pun hodo kake-te sanchou made hitori de noboru.

'Dengan mobil butuh waktu 20 menit sampai di kaki gunung desa Chihayaakasaka Osaka, kemudian butuh waktu sekitar 1 jam 10 menit untuk naik sendirian sampai di puncak.'

(Fukuda, 2018)
(4-5) Hobo mainichi, hyokou yaku 870 meetoru no Kanazakura jinja made sakamichi o nobotte iku.

'Kurang lebih setiap hari, menaiki tanjakan sampai kuil Kanazakura dengan ketinggian 870 meter.'

(Tanaka, 2018)

(4-6) Koten de wa, ki ni noboru sugata ya giniro no senaka o motsu osu no gorira nado 30 ten no e o tenji.

Di pameran, terdapat lukisan gorila jantan berpunggung perak yang sedang naik pohon dan 30 lukisan lainnya.

(Kogi, 2018)

Berdasarkan data sebelumnya, verba noboru menunjukkan tindakan seseorang bergerak ke suatu tempat. Verba noboru menghasilkan polisemi BERGERAK/TERJADI dengan pola sintaksis ' $\mathrm{X}$ bergerak ke $\mathrm{Y}$ '. Entitas yang dikenai tindakan berupa tempat yang lebih tinggi dari pelaku tindakan, seperti gunung, tanjakan, pohon, dan lain sebagainya. Hal ini membentuk komponen ' $\mathrm{Y}$ berada di atas posisi X'. Berbeda halnya dengan verba noru, verba noboru lebih menekankan cara seseorang dalam melakukan tindakan 'naik'. Dalam hal ini, verba noboru menunjukkan seseorang naik dengan cara mendaki, menanjak, memanjat, dan sebagainya. Hal ini membentuk komponen ' $\mathrm{X}$ bergerak dengan cara tertentu'. Berdasarkan pemaparan ini, verba noboru dapat diparafrasekan sebagai berikut. 


\begin{abstract}
Noboru
'naik/memanjat/mendaki/menanjak'

pada waktu itu, $\mathrm{X}$ bergerak ke $\mathrm{Y}$

$\mathrm{Y}$ berada di atas posisi $\mathrm{X}$

$\mathrm{X}$ bergerak dengan cara tertentu (mendaki, memanjat, menanjak)

$\mathrm{X}$ menginginkan ini

X melakukan sesuatu seperti ini
\end{abstract}

\subsection{Struktur Semantis Verba Agaru}

Verba agaru memiliki makna 'bergerak dari tempat yang rendah menuju tempat yang lebih tinggi secara keseluruhan atau sebagian' (Shinmeikai, 1989:10). Hirose (2001:3) mengungkapkan verba agaru menyatakan 'bergerak ke atas, dengan fokus hasil dari pergerakan, seperti tujuan, lokasi atau tingkat'. Berikut dipaparkan kalimat yang mengandung verba noboru.

(4-7) 2-kai ni agaru to, yane no shita ni ataru koyagumi ga arawareta.

'Kalau naik ke lantai 2, terlihat susunan rangka di bawah atap.'

(Numata, 2018)

(4-8) Toujitsu, himago no Matsuho chan (3) ya Aiko chan-ra kazoku to tomo ni suteeji ni agaru no o tanoshimi ni shite iru.

'Hari itu, sang cicit yaitu Matsuho (3) dan Aiko beserta keluarga bersama-sama naik ke panggung dan bersenang-senang.'

(Miyazaki, 2018)

Berdasarkan data sebelumnya, verba agaru menunjukkan tindakan seseorang naik ke atas sesuatu. Verba agaru menghasilkan polisemi BERGERAK/TERJADI dengan pola sintaksis ' $\mathrm{X}$ bergerak ke $Y^{\prime}$. Entitas yang dikenai tindakan berupa tangga, panggung, dan lain sebagainya. Hal ini dapat diformulasikan dengan ' $Y$ berada di atas posisi X'. Verba agaru memiliki kemiripan dengan noboru. Namun verba agaru lebih memfokuskan pada hasil tindakan. Dalam hal ini, hasil yang ingin dicapai verba agaru ialah menuju tempat yang berada di atas dari posisi awal. Hal ini dapat diformulasikan dengan komponen 'karena ini, $\mathrm{X}$ berada di atas dari posisi awal'. Berdasarkan pemaparan ini, maka verba agaru dapat diparafrasekan sebagai berikut.

\author{
Agaru 'naik' \\ pada waktu itu, $\mathrm{X}$ bergerak ke $\mathrm{Y}$ \\ $\mathrm{Y}$ berada di atas posisi $\mathrm{X}$ \\ karena ini, $\mathrm{X}$ berada di atas dari posisi \\ awal \\ $\mathrm{X}$ menginginkan ini \\ $\mathrm{X}$ melakukan sesuatu seperti ini
}

\section{SIMPULAN}

Berdasarkan hasil analisis, dapat diketahui bahwa verba 'naik' dalam bahasa Jepang terdiri atas leksikon noru, noboru, dan agaru. VNBJ merepresentasikan prototipe action, event, and movement. VNBJ memiliki makna asali BERGERAK yang berpolisemi dengan makna asali TERJADI. Pola sintaksis yang 
dibentuk VNBJ ialah 'X bergerak ke Y'. Perbedaan masing-masing verba noru, noboru, dan agaru terlihat dari entitas, cara, tujuan, dan hasil akhir.

Verba noru menunjukkan seseorang bergerak ke atas atau ke dalam sesuatu, seperti bus, kuda, lift, dan lain sebagainya. Verba noru mengindikasikan tujuan seseorang ingin bergerak ke suatu tempat. Verba noboru menunjukkan seseorang bergerak dengan cara tertentu, seperti mendaki, memanjat, menanjak, dan lain sebagainya. Entitas yang digunakan verba noboru berupa gunung, pohon, tanjakan, dan lain sebagainya. Verba agaru menunjukkan hasil seseorang yang berada di atas dari posisi awal. Entitas yang digunakan verba agaru berupa tangga, panggung, dan lain sebagainya.

\section{DAFTAR PUSTAKA}

Citrawati, Dewa Ayu Carma. 2018. "Nomina Berelasi Air yang Dihasilkan Entitas Dalam Bahasa Bali". Linguistika, Maret 2018 p-ISSN: 0854-9613. Vol. 48 No. 25.

Goddard, Cliff. 1996. "Building a Universal Semantic Metalanguage: The Semantic Theory of Anna Wierzbicka". Canberra: The Australian National University.

Goddard, Cliff and Wierzbicka, Anna. 2014. Words and Meanings: Lexical Semantics across Domains, Language, and Cultures. United Kingdom: Oxford University Press.
Hirose, Masayoshi. 2001. Effective Japanese Usage Dictionary. Tokyo: Kodansha.

Ikuta, Daisuke. 2018. "Kaigoshisetsu de no mitori, zouka kuni mo ato oshi”. Diakses melalui website: https://www.asahi.com/articles/ASL214W VDL21UBQU012.html?iref=pc_ss _date pada 31 Mei 2018.

Kano, Kohei. 2018. "Niigata Shizoku Kanou na Basu Tojou Niigata-shi no BRT'. Diakses melalui website: https://www.asahi.com/articles/ASL3R6K S6L3RUOHB014.html?ir ef=pc_ss_date pada 31 Mei 2018.

Kogi, Yuuta. 2018. "Kagawa, Matsuko-san Shousan Gorira Babaa Abe-san no Koten". Diakses melalui website:https://www.asahi.com/articles/A SL566KG3L56PLXB001.html?iref=pc_s s_date pada 31 Mei 2018

Miyazaki, Sonoko. 2018. "Hiroshima, Douyou 100-gyoku Utaou "Akai Shima" Soukan 100-nen Kinen". Diakses melalui website https://www.asahi.com/articles/ASL5X51 G6L5XPITB012.html?iref=pc_ss_date pada 31 Mei 2018.

Murano, Eiichi. 2018. "Kanagawa, Takashima Masanobu-san Futatabi Ujimasa ni Odawara Houjou Godai Matsuri". Diakses melalui website http://www.asahi.com/articles/ASL2R4S0 JL2RULOB00S.html?iref=pc_ss_date pada 31 Mei 2018

Numata, Chikako. 2018. "Ishikawa, Dai 9 Shidan Shireibu Chousha to Kanazawa Kaikousha no Naibu Koukai”. Diakses melalui website https://www.asahi.com/articles/ASL5M52 93L5MPJLB007.html?iref=pc_ss_date pada 31 Mei 2018. 
Shinmeikai. 1989. Kokugo Jiten. Tokyo: Sanseidou.

Sudaryanto. 2015. Metode dan Aneka Teknik Analisis Bahasa. Yogyakarta: Sanata Dharma University Press.

Suputra, Gusti Ketut Alit. 2016. "The Meaning of the Balinese 'To Eat': A Study of Natural Semantic Metalanguage (NSM)". Diakses melalui website https://ojs.unud.ac.id/index.php/eol/article /view/18945/12412 pada 31 Mei 2018.

Tanaka, Motoyuki. 2018. "Hitori Jitensha-bu, Zenkoku V Katamichi 10 Kiro no Tsuugaku Kikkake”. Diakses melalui website https://www.asahi.com/articles/ASK5M4 WR3 K5MUZOB009.html?iref=pc_ss_date pada 31 Mei 2018.

Wierzbicka, Anna. 1996. Semantics: Prime and Universal. Oxford: Oxford University. 